\title{
Mood induction and the priming of semantic memory in a lexical decision task: Asymmetric effects of elation and depression
}

\author{
BRADFORD H. CHALLIS and RICHARD V. KRANE \\ Acadia University, Wolfuille, Nova Scotia, Canada
}

\begin{abstract}
A number of predictions derived from Bower's (1981) associative network model of mood and memory were investigated by inducing elated, neutral, or depressed moods in different groups of subjects. A mood-evaluation checklist verified the success of the mood-induction procedure. While in induced moods, subjects performed a lexical decision task in which the target stimuli were positive or negative trait adjectives, neutral nontrait adjectives, or nonwords. As predicted, subjects in elated moods showed facilitated processing of positive target words relative to processing of negative and neutral target words. Contrary to prediction, subjects in depressed moods did not respond faster to negative target words than they did to positive target words. Following the lexical decision task, subjects were administered an incidental free recall test for the words presented during the lexical decision task. Contrary to prediction, the three mood groups recalled similar numbers of words for each type of word target category. The asymmetric effects of elation and depression on memory that were observed in this study and a number of other studies are discussed.
\end{abstract}

Fundamental to the predictive validity of Bower's (1981) associative network model of memory and emotion are two assumptions. The first is that specific emotions are represented as separate nodes in the same associative network as are words, concepts, and propositions of a verbal symbolic nature. The second assumption is that activation of an emotion node, by whatever means, will serve to lower the threshold of excitation of an associatively linked node via the process of spreading activation. This activation should increase the likelihood that related information would become more accessible to consciousness than it otherwise would, or at least become more accessible than information not associatively linked to the emotion node.

Given these assumptions, one may well expect semantic memory tasks involving the automatic spread of activation to reveal differential mood priming effects. For example, one may expect the experimental induction of positive and negative moods to differentially affect the perceptual threshold for recognizing words expressing positive and negative affect (i.e., mood-congruent and mood-incongruent words). However, contrary to expectation, Gerrig and Bower (1982) failed to obtain evidence of such mood priming effects in an experiment in which a happy or angry mood was experimentally induced in different groups of subjects via a hypnotic induction technique prior to their performing a perceptual threshold task.

This research constituted a master's thesis submitted to Acadia University by the first author, under supervision of the second author, and was presented at the Canadian Psychological Association meeting in Toronto in June 1986. We thank Verne Bacharach, Elizabeth Blackmer, Ray Klein, James Neely, and Henry Roediger for helpful comments. Requests for reprints should be sent to Bradford Challis, Department of Psychological Sciences, Purdue University, West Lafayette, IN 47907.
In a similar vein, Gotlib and McCann (1984) failed to observe an effect of induced mood on either response latency or probability of recall of mood-congruent or moodincongruent words presented in a Stroop color-naming task, which also is presumed to reflect the automatic spread of excitation.

Recognizing the possibility that such null effects may reflect an insensitivity of the experimental tasks to the influence of induced mood, the present research examined the effect of induced mood on subjects' performance in a lexical decision task. Neely's (1977) research, among others, showed the reaction time measures of the lexical decision task to be acutely sensitive to the effects of a variety of independent variables (e.g., stimulus onset asynchrony, semantic relatedness) presumed to influence the spread of activation. Thus, in the present study, subjects in experimentally induced elated, neutral, or depressed moods performed a lexical decision task. The target letter strings to be classified as words or nonwords were positive or negative trait adjectives, neutral nontrait adjectives (referred to hereafter simply as positive, negative, and neutral words, respectively), or nonwords. Following completion of the lexical decision task, an incidental free recall task was administered in which the subjects attempted to recall the target words presented during the lexical decision task.

The general form of the hypothesis, upon which a variety of within-group and between-group tests of Bower's (1981) model were based, was that the induction of a specific mood in one group of subjects would serve to lower the threshold of activation of those subjects, as compared with other groups of subjects, for mood-congruent words, as compared with mood-incongruent words or neutral words. As a consequence, subjects in a depressed 
mood (to take but one example), compared with subjects in elated or neutral moods, were expected to exhibit both a more rapid response latency during the lexical decision task and a greater probability of recall during a subsequent surprise free recall test for depressed-content words than for elated-content or neutral-content target words presented during the lexical decision task.

\section{METHOD}

\section{Subjects}

Thirty-six subjects ( 23 females, 13 males), recruited from an introductory psychology course at Acadia University, participated in the experiment. All subjects received partial course credit for their participation.

\section{Materials}

Screening procedure. Upon arriving at the laboratory, all potential subjects were administered the revised version of the Beck Depression Inventory (BDI; Beck, 1976) so as to prevent naturally depressed subjects from participating in the study.

Mood-induction materials. Each subject was induced into an elated, depressed, or neutral mood by reading the mood-induction statements developed by Velten (1968) and modified by Coleman (1975). Coleman modified Velten's statements into cognitively oriented self-referent attitude statements that avoided any mention of mood, but still induced the expected mood in subjects reading the statements in a manner consistent with Velten's procedure.

The 60 mood-induction statements of each mood-induction condition were typed individually on $15 \times 10 \mathrm{~cm}$ white cards and arranged sequentially in a deck. Included in Coleman's (1975) induction procedure is a set of standard instructions designed to teach the subject how to talk himself/herself into a psychological attitude: Subjects are instructed to read each statement aloud once, to read it to themselves once, and to concentrate their full attention on the idea expressed on each card.

Assessment of mood induction. The effectiveness of the moodinduction procedure was assessed using the Depression Scale of the Multiple Affect Adjective Check List (MAACL; Zuckerman \& Lubin, 1965). The Depression Scale items consist of 20 negative-mood adjectives (e.g., sad, suffering, lost) and 20 positive-mood adjectives (e.g., strong, lucky, enthusiastic). The subjects were instructed to mark an $\mathrm{X}$ beside the words that described how they felt at the time they were participating. Total scores on the checklist range from 0 to 40 , with low scores indicating an elated mood and high scores indicating a depressed mood.

Target-stimulus materials. Sets of 18 positive and 18 negative personality-trait adjectives and 18 neutral nontrait adjectives were selected from word norms so that the three sets of target words were matched on word frequency and word length. The sets of target words did not include any word that occurred in the mood-induction statements or in the MAACL. The 18 nonword target letter strings were selected from the nonwords used by Neely (1977), and were selected by matching the frequency of the words from which the nonwords were formed with the frequency of the words constituting the word targets in the present study. Neely constructed his nonword targets by changing one letter in a word to form a letter string that is not an English word.

The positive target words were joyous, superb, lively, talented, likable, delighted, trusting, pleased, excellent, ambitious, admired, clever, sociable, romantic, hopeful, lovable, cheery, and smiling. The negative target words were deprived, dreadful, plagued, oppressed, doomed, guilty, dull, sick, beaten, defeated, boring, diseased, shameful, ignorant, failed, ruined, cursed, and damned. The neutral target words were optical, regional, linear, framed, porous, mineral, retail, hybrid, adjacent, curved, yearly, soluble, vertical, algebraic, migratory, printed, nautical, and aquatic.

A one-way analysis of variance (ANOVA) revealed no significant differences among the four types of targets in terms of either the word frequency ratings (Carroll, Davies, \& Richman, 1971) $[F(3,68)<1]$ or the word lengths $[F(3,68)=1.12, p=.35]$. For the nonword fre- quency rating, the frequency of the words from which the nonwords were formed was used.

Target-list construction. A practice list that consisted of 18 neutral word targets and 6 nonword targets combined in random order was constructed for use on 24 practice trials of the lexical decision task. No word or nonword target occurred in both the practice list and the experimental list. The experimental list was constructed by randomly selecting a neutral, a positive, and a negative word target and a nonword target from the preselected stimulus materials, and randomly combining them into a block of four different target types. The 18 blocks formed in this fashion were then randomly ordered to form the 72 experimental trials, the order of presentation of which was reversed for one-half of the subjects in each mood-induction group.

Testing apparatus. The target stimuli were typed, in capital Roman letters, on opaque plastic and placed into $35-\mathrm{mm}$ slide holders. The slides were projected onto a Handy rear-projector screen by means of a Kodak Ektagraphic slide projector. The letter $\mathrm{H}$ projected on the screen in this fashion measured $24 \mathrm{~mm}$ high $\times 21 \mathrm{~mm}$ wide. Lafayette timers controlled the duration of target presentation, by opening and closing a Gerbrands shutter fitted on the lens of the slide projector, and controlled the duration of the warning tones and blank intervals. A Lafayette clock measured, in milliseconds, the subjects' reaction times (RTs), that is, the time between onset of the target letter string and a subject's keypress response. A Lafayette tone generator produced the warning tones.

\section{Procedure}

Prior to being accepted for participation in the experiment, the subjects completed the BDI. A score of 16 or higher is often considered an indication of moderate depression (Beck, 1976) and was therefore selected as the subject exclusion score.

At the start of the experimental session, each subject was seated at a table with the projection screen located approximately $1 \mathrm{~m}$ in front of the subject, and a pair of response keys was positioned between the subject and the screen. A standard set of instructions concerning performance of the lexical decision task was read aloud, informing the subject that his/her task was to decide as quickly as possible whether the string of letters projected on the screen was or was not an English word, and to respond accordingly by pressing the key marked WORD or the key marked NONWORD. The position of the WORD/NONWORD keys was counterbalanced across subjects. Prior to each stimulus presentation and keypress response, the subject positioned the index finger of each hand on a white square located beside the response key for that hand. The importance of responding as quickly as possible, while maintaining high accuracy, was emphasized. After the instructions had been read and questions concerning the task had been answered, the subjects completed 24 practice trials.

A 1-sec tone marked the beginning of each trial and was followed $1 \mathrm{sec}$ later by the presentation of the target letter string to which the subject made the speeded word/nonword response. The target letter string remained displayed for $2 \mathrm{sec}$. There was a 4-sec interval before the tone sounded again to mark the beginning of another trial. Upon completing the practice session, the subjects were informed that they would return to the lexical decision task shortly, but that it first was necessary for them to read a series of statements.

Each subject was randomly assigned to one of the three mood-induction groups and was handed the set of instruction cards and mood-induction statements appropriate to the condition to which he/she had been assigned. The subject was instructed to begin reading the first statement card at the sound of a tone and to proceed to the next card at the sound of each tone. A 1-sec tone sounded at the end of each 10-sec interval, so that $11 \mathrm{~min}$ were required for the subject to read through all 60 moodinduction statements.

Immediately following the mood-induction procedure, completion of the mood-evaluation checklist, and a second reading of the latter half of the 60 mood-induction statements, the experimental trials of the lexical decision task were initiated. An experimental trial followed precisely the same format as the practice trials described above. Upon completion of the 72 experimental trials, which required approximately $10 \mathrm{~min}$ to complete, the subjects were asked to write down, in any order, 
the target words that they could remember. The subjects were informed that they had $5 \mathrm{~min}$ for the recall task, and were instructed to guess if in doubt about a word.

\section{RESULTS}

\section{Screening Procedure}

Three students were not allowed to serve as subjects in the experiment because their BDI scores exceeded the maximum allowable total of 15 . They were replaced by subjects who met the BDI criterion. A one-way ANOVA conducted on the BDI scores of subjects in the elated, neutral, and depressed mood-induction groups revealed no reliable differences in the mean depression scores prior to the mood-induction procedure $[F(2,23)<1]$; the mean BDI scores were 5.8 for the elated group, 5.8 for the neutral group, and 7.1 for the depressed group.

\section{Assessment of Mood Induction}

A one-way ANOVA of the mood-evaluation checklist scores revealed a significant main effect for mood $[F(2,23)$ $=36.42, p<.001]$. A Newman-Keuls post hoc analysis indicated that the checklist scores of the three moodinduction groups differed significantly $(p<.05)$ in the predicted directions: the elated mood group obtained the lowest mean score $(M=3.42)$, the depressed mood group obtained the highest mean score $(M=26.92)$, and the neutral mood group obtained an intermediate mean score $(M=10.00)$.

\section{Effect of Mood on Lexical Decision}

Response latencies. The mean latency to respond correctly to each of the four types of targets presented during the lexical decision task was calculated for each subject over the 18 trials of each type of target. Table 1 presents the mean and standard deviation of the response latencies of each mood-induction group for each of the three word target conditions and the nonword target condition. A $3 \times 3$ mixed-design ANOVA of the mean latency scores of subjects in the elated, neutral, and depressed mood groups to correctly respond to the positive, negative, and neutral word targets revealed a significant main effect of type of word target $[F(2,66)=65.39, p<.001]$ and a significant interaction between mood group and type of word target $[F(4,66)=2.70, p<.05]$.
An analysis of the simple effects involving the withingroups variable, type of word target, revealed a significant simple effect of word type for the elated mood group $[F(2,22)=29.16, p<.001]$, the neutral mood group $[F(2,22)=8.86, p<.01]$, and the depressed mood group $[F(2,22)=36.34, p<.001]$. Within each mood group, simple comparisons were made of the mean latency to respond to the positive, neutral, and negative target words, thus providing tests of specific hypotheses derived from the general hypothesis presented in the introduction. Consistent with Bower's (1981) model, subjects in the elated mood group responded significantly faster to positive words than to negative words $[F(1,11)$ $=22.92, p<.001]$ and significantly faster to positive words than to neutral words $[F(1,11)=41.78$, $p<.001]$; however, elated mood subjects also responded significantly faster to negative words than to neutral words $[F(1,11)=16.14, p<.01]$. Of greater import for Bower's model was the finding that depressed subjects did not respond significantly faster to negative words than to positive words $[F(1,11)=1.25, p>.25]$; moreover, like elated subjects, depressed subjects responded significantly faster to both positive and negative words than to neutral words $[F \mathrm{~s}(1,11)=84.17$ and 29.90 , respectively, $p s<.001]$. Finally, subjects in the neutral mood group responded to the different word types in a manner similar to that observed for subjects in the depressed mood group: Neutral mood subjects responded to both the positive and negative word targets significantly faster than they responded to the neutral word targets $\left[F_{\mathrm{s}}(1,11)=11.09\right.$ and 10.71 , respectively, $p s<.01$ ], but did not respond reliably differently to the positive and negative words $[F(1,11)<1]^{1}$

Additional outcomes incompatible with those expected on the basis of Bower's (1981) model were revealed by an analysis of the simple effects involving the betweengroups factor, type of induced mood. The analysis revealed no reliable differences among the three groups (elated, neutral, depressed) in mean RTs on the positive, the negative, or the neutral word targets $[F \mathrm{~s}(2,33)<1$, in all cases].

Error rates. Three subjects were dropped from the experiment because their overall error rates exceeded $10 \%$ : 2 elated mood subjects whose error rates were $11.1 \%$ and $13.8 \%, 1$ neutral mood subject whose error rate was

Table 1

Mean Reaction Time and Percent Error on the Lexical Decision Task, and Mean Number of Words Recalled on the Incidental Free Recall Task, for Positive (POS), Negative (NEG), Neutral (NEU), and Nonword (NON) Targets in the Elated, Depressed, and Neutral Mood-Induction Groups

\begin{tabular}{|c|c|c|c|c|c|c|c|c|c|c|c|c|c|c|c|c|c|c|c|}
\hline \multirow[b]{4}{*}{ Group } & \multicolumn{19}{|c|}{ Dependent Measure } \\
\hline & \multicolumn{8}{|c|}{ Reaction Time } & & & & & \multicolumn{7}{|c|}{ Words Recalled } \\
\hline & \multicolumn{2}{|c|}{ POS } & \multicolumn{2}{|c|}{ NEG } & \multicolumn{2}{|c|}{ NEU } & \multicolumn{2}{|c|}{ NON } & \multicolumn{4}{|c|}{ Percent Error } & \multicolumn{2}{|c|}{ POS } & \multicolumn{2}{|c|}{ NEG } & \multicolumn{2}{|c|}{ NEU } & \multirow[b]{2}{*}{ NON } \\
\hline & $M$ & $S D$ & $M$ & $S D$ & $M$ & $S D$ & $M$ & $S D$ & POS & NEG & NEU & NON & $M$ & $S D$ & $M$ & $S D$ & $M$ & $S D$ & \\
\hline lat & 796 & 98 & 57 & 120 & 934 & 154 & 1070 & 181 & 4.6 & 0.9 & 8.3 & 6.5 & 2.50 & 1.57 & 1.58 & 1.44 & 2.92 & 1.83 & - \\
\hline Depressed & 845 & 185 & 861 & 153 & 977 & 213 & 1192 & 221 & 3.2 & 4.2 & 4.6 & 2.8 & 2.33 & 1.15 & 2.33 & 1.37 & 2.42 & 1.62 & - \\
\hline Neutral & 827 & 164 & 841 & 167 & 903 & 148 & 1113 & 253 & 0.9 & 2.3 & 8.8 & 6.5 & 2.08 & 0.90 & 3.00 & 0.95 & 2.67 & 1.30 & - \\
\hline
\end{tabular}

Note-Reaction times are in milliseconds. 
$12.5 \%$, and 1 depressed mood subject whose error rate was $12.5 \%$. They were replaced by subjects who met the error rate criterion. The percentages of errors committed by each mood-induction group for each type of word target are presented in Table 1. Response latencies in conjunction with the error rates do not support a speedaccuracy trade-off.

\section{Effect of Mood on Recall}

Immediately following the lexical decision task, the subjects attempted to recall as many as they could of the three types of target words presented during the lexical decision task. The means and standard deviations for the number of words correctly recalled by subjects in each of the three mood groups for each type of target word are presented in Table 1 . A $3 \times 3$ mixed-design ANOVA revealed no significant main effect of type of word target $[F(2,66)<1]$ or mood group $[F(2,33)<1]$ and no significant word target $\times$ mood group interaction $[F(4,66)$ $=2.07, p>.10]$.

\section{DISCUSSION}

As predicted, subjects in an elated mood showed facilitated processing of positive target words relative to processing of negative and neutral target words. Contrary to prediction, subjects in a depressed mood did not respond faster to negative words than they did to positive words. The obvious problem is that of explaining the absence of the predicted facilitation effect in the depressed group while maintaining the integrity of Bower's (1981) model.

Although it is possible that a truly depressed mood was not in fact induced in subjects in the depressed mood group, the evidence would appear to suggest otherwise. Subjects in the depressed mood group scored significantly higher on the mood-evaluation checklist than did subjects in the neutral and elated mood groups; moreover, at the end of the experimental session, subjects in the depressed mood group generally reported that a depressed mood had in fact been induced. Although not reliable statistically, depressed subjects did respond more slowly to all target types than did subjects in the other two mood conditions; this is in accord with previous findings (e.g., Coleman, 1975; Velten, 1968) of slower motor responses on the part of subjects in a depressed mood.

According to Bower's (1981) model, a critical factor determining whether or not spreading activation effects are obtained is the strength of the associative relationship between a mood and a related word. In selecting negative target words for the present study, the tendency was to select words that other investigators have labeled as "depressed-content" words (e.g., doomed, ruined, beaten); thus, it may be that the negative words were more strongly associated with the depressogenic constructs of the negative self-schema of severe depression (e.g., Beck, 1976) than with the memory node postulated to represent depressed mood.

It must be recognized, however, that the asymmetric effects of elation and depression found in the present study complement the findings of several other mood-induction studies (see reviews by Blaney, 1986, and Isen, 1985). Regardless of the manner of induction, it appears that induction of an elated mood generally facilitates the processing of positive material, whereas induction of a depressed mood does not generally facilitate the processing of negative material. In attempting to understand the reasons for the asymmetry observed in the present study, it is of interest to note that the asymmetrical mood-induction effects observed in the studies cited by Isen (1985) were obtained with memory tasks involving controlled processing of episodic information; each of the few studies that examined the effects of induced mood via memory tasks that involve automatic processing of semantic information failed to find a significant mood priming effect (Blaney, 1986) for either elated mood induction or depressed mood induction in relation to the processing of either positive-, negative-, or neutral-content words. Thus, the null effects reported by Clark, Teasdale, Broadbent, and Martin (1983) in the context of a lexical decision task; by Gerrig and Bower (1982) in the context of a perceptual threshold task; and by Gotlib and McCann (1984) in the context of a Stroop color-naming task, suggest that semantic memory tasks and/or tasks involving automatic processing may be particularly insensitive to the effects of different mood states. Given that the present study is the first to report asymmetric mood-induction effects in the context of a memory task that involves the automatic processing of semantic information, future research should attempt to determine the critical variables responsible for the asymmetric effects and the boundary conditions within which the effects may be obtained.

\section{REFERENCES}

BECK, A. T. (1976). Cognitive therapy and the emotional disorders. New York: International Universities Press.

Blaney, P. H. (1986). Affect and memory: A review. Psychological Bulletin, 99, 229-246.

Bower, G. H. (1981). Mood and memory. American Psychologist, 36, 129-148.

Carroll, J. B., Davies, P., \& Richman, B. (1971). The American Heritage word frequency book. New York: Houghton Mifflin.

Clark, D. M., Teasdale, J. D., Broadbent, D. E., \& Martin, M. (1983). Effects of mood on lexical decisions. Bulletin of the Psychonomic Society, 21, 175-178.

Coleman, R. E. (1975). Manipulation of self-esteem as a determinant of mood of elated and depressed women. Journal of Abnormal Psychology, 84, 693-700.

Gerrig, R. J., \& Bower, G. H. (1982). Emotional influence on word recognition. Bulletin of the Psychonomic Society, 19, 197-200.

Gotlib, I. H., \& MCCANN, C. D. (1984). Construct accessibility and depression: An examination of cognitive and affective factors. Journal of Personality \& Social Psychology, 47, 427-439.

ISEN, A. M. (1985). Asymmetry of happiness and sadness in effects on memory in normal college students: Comment on Hasher, Rose, Zacks, Sanft, and Doren. Journal of Experimental Psychology: General, 114, 388-391.

NeEly, J. H. (1977). Semantic priming and retrieval from lexical memory: Roles of inhibitionless spreading activation and limitedcapacity attention. Journal of Experimental Psychology: General, 106, 226-254.

VELTEN, E. (1968). A laboratory task for the induction of mood states. Behavior Research \& Therapy, 6, 473-482.

Zuckerman, M., \& Lubin, B. (1965). Manual for the Multiple Affect Check List. San Diego: Educational and Industrial Testing Service.

\section{NOTE}

1. All three mood induction groups responded significantly slower to neutral words than to positive and negative words. Although the three groups of words were matched on word frequency and word length, other orthographic or phonological differences, or the differences in emotionality, may account for the slower responses to the neutral words.

(Manuscript received for publication December 3, 1987.) 